\title{
An Analysis of the Effects of Acute and Chronic Fluoxetine on Extracellular Norepinephrine in the Rat Hippocampus during Stress
}

Michelle E. Page, Ph.D., and Elizabeth D. Abercrombie, Ph.D.

The locus coeruleus (LC) noradrenergic system is activated by a range of arousing and stressful stimuli. The serotonergic inputs to this structure have been shown to attenuate $L C$ activation under some conditions. The present study examined the effect of fluoxetine, a selective serotonin reuptake inhibitor (SSRI) known to be a clinically effective antidepressant, on basal and stress-induced norepinephrine (NE) release. Basal and stress-induced NE efflux in the rat hippocampus were assessed using in vivo microdialysis techniques. The effect of a 30 minute tailpinch stressor on extracellular concentration of $N E$ was compared in rats treated with fluoxetine either once prior to tailpinch or twice daily for 14 days and, respectively, in unhandled controls and vehicle-treated control animals. A single fluoxetine injection prior to tailpinch did not significantly alter the tailpinch-induced increase of extracellular NE as compared to naive controls. However, there was an enhanced NE response to tailpinch in chronic fluoxetine versus chronic vehicle-treated control rats. Thus, acute blockade of 5-HT uptake by fluoxetine does not affect NE release in response to tailpinch stress. Chronic fluoxetine administration, however, results in a potentiated evoked response of the $L C-N E$ system. One action of chronic fluoxetine, which may relate to therapeutic efficacy, is an increase in responsivity of $L C$ neurons.

[Neuropsychopharmacology 16:419-425, 1997]

(C) 1997 American College of Neuropsychopharmacology
KEY WORDS: Locus coeruleus; Fluoxetine; In vivo microdialysis; Norepinephrine; Stress

Alterations in noradrenergic and serotonergic function have long been implicated in depression because clinically effective antidepressants directly interact with these systems and produce observable changes in depressive symptomatology (Schildkraut 1965; Iversen 1975; Owens and Nemeroff 1994). The first generation of antidepressants to be widely prescribed included tricyclic compounds such as imipramine, desipramine, and amitriptyline, and monoamine oxidase inhibitors, such as phenylzine and tranylcypromine. These com-

Address correspondence to: Michelle E. Page, Ph.D., Center for Molecular and Behavioral Neuroscience, Rutgers University, 197 University Avenue, Newark, NJ 07102.

Received September 6, 1996; accepted November 12, 1996. pounds in general have more potent actions on the biochemistry of central noradrenergic systems (Richelson and Pfenning 1984; Heninger and Charney 1987). The emergence of selective serotonin reuptake inhibitors (SSRIs) as the treatment of choice for depression has shifted the recent emphasis of the monoamine theory of affect toward serotonergic mechanisms rather than noradrenergic dysfunction (Baldwin and Rudge 1995; el Mansari et al. 1995; Stanford 1996; Wong et al. 1995). The present study was designed to test the hypothesis that SSRIs may be effective in part by altering serotonergic modulation of the pontine noradrenergic nucleus, the locus coeruleus (LC). Such a model provides a common mechanistic link between effective antidepressants interacting primarily with central noradrenergic versus serotonergic systems.

Several pieces of data support the idea that serotonergic afferents modulate noradrenergic neuronal activity 
in the LC. Serotonergic immunoreactive fibers provide a dense innervation of the LC area (Palkovits et al. 1974; Leger and Descarries 1978; Pickel et al. 1977). Serotonin (5-HT) attenuates sensory-evoked responses of LC neurons (Segal 1979) and decreases glutamate-induced excitation of these cells when applied locally (Bobker and Williams 1989; Aston-Jones et al. 1991; Charlety et al. 1991). The evoked response of LC neurons to repeated sciatic nerve stimulation is enhanced in rats pretreated with the 5-HT synthesis inhibitor p-chloro-phenylalanine (PCPA) and is attenuated in rats treated with the 5-HT precursor 5-HTP (Shiekhattar and Aston-Jones 1993).

Exposure to stress and inability to adequately cope with stress are regarded as important etiological factors associated with the emergence of abnormal affective states (Anisman and Zacharko 1982). It therefore is perhaps significant that stressful stimuli have been shown to elevate indices of activity in both central NE and 5-HT systems. The activity of $\mathrm{LC}$ neurons increases in response to a variety of environmental and physiological challenges (Elam et al. 1986; Abercrombie and Jacobs 1987; Morilak et al. 1987; Curtis et al. 1993). The turnover of NE and 5-HT is increased in forebrain regions following exposure to stressful stimuli (Thierry et al. 1968; Korf et al. 1973; Dunn 1988; Corley et al. 1992). In vivo microdialysis studies have directly shown stress-induced increases in extracellular concentrations of NE and 5-HT in the hippocampus (Abercrombie et al. 1988; Kalen et al. 1989). Thus, the modulation of LC activity by $5-\mathrm{HT}$ may be important for appropriate behavioral responding to stress.

In summary, as with other effective antidepressants, although the primary pharmacological action is understood, little is known regarding the ultimate mechanism(s) of action of the SSRIs that serve to confer therapeutic efficacy. One possibility is that affective disorders are the result of a disruption of some appropriate level of balance among central monoaminergic systems (Schatzberg and Schildkraut 1995). As described, a likely site for SSRIs such as fluoxetine to interact with the noradrenergic system of the LC is at the level of 5-HT inputs to the LC cell bodies. The goal of the present study was to determine whether one action of fluoxetine is to alter the responsivity of noradrenergic LC neurons to stress after acute or chronic administration. We examined the ability of acute and chronic fluoxetine administration to alter NE release in an LC terminal field, the dorsal hippocampus, under basal conditions and in response to presentation of an acute stressor.

\section{METHODS}

\section{Animals}

Male Sprague-Dawley rats (Zivic-Miller Laboratories, Pittsburgh, PA) weighing 250 to $300 \mathrm{gm}$ at the start of treatment were maintained on a 12-hour light-dark cy- cle with food and water available ad libitum. Animals that were not handled prior to the experiment were housed individually in plastic shoebox cages, and animals that received chronic pretreatment injections were housed individually in hanging wire cages. All procedures were performed in accordance with guidelines published in the NIH Guide for Care and Use of Laboratory Animals (NIH, 1985), and all protocols were approved by the Rutgers University Institutional Animal Care and Use Committee.

\section{Drug Treatments and Experimental Design}

Fluoxetine (Eli Lilly, Indianapolis, IN) was dissolved in $\mathrm{dH}_{2} \mathrm{O}$ and was administered by IP injection at a dose of $5 \mathrm{mg} / \mathrm{kg}$. This dose was selected because in preliminary studies with chronic fluoxetine we observed that treatment with $10 \mathrm{mg} / \mathrm{kg}$ of the drug produced anorexia and unacceptable rates of weight loss in the animals.

In the study of the acute effects of fluoxetine, rats received a single IP injection of drug 75 minutes prior to stress exposure. The control group consisted of naive, unhandled animals. Animals treated with chronic fluoxetine were injected twice daily for 14 days (Byerley et al. 1988; Caccia et al. 1992; Trouvin et al. 1993); control animals received vehicle injections on the same schedule. In these animals, the neurochemical effects of stress were evaluated approximately 18 hours after the last injection.

Stress exposure consisted of a tailpinch stimulus. An artery forcep (Fisher \#13-812-4) was applied approximately $5 \mathrm{~cm}$ from the tip of the tail and was left in place for 30 minutes.

\section{Dialysis Probe Calibration}

Vertical concentric microdialysis probes with a $2 \mathrm{~mm}$ active region of dialysis membrane were used (for details see Abercrombie et al. 1988). To characterize the in vitro recovery rate, probes were calibrated prior to implantation by being placed in a beaker containing artificial cerebrospinal fluid (aCSF: $147 \mathrm{mM} \mathrm{NaCl}, 2.5 \mathrm{mM} \mathrm{KCl}, 1.3$ $\mathrm{mM} \mathrm{CaCl}_{2}, 0.9 \mathrm{mM} \mathrm{MgCl}_{2} ; \mathrm{pH} 7.4$ ) to which NE standard $(0.5 \mu \mathrm{M})$ was added. However, because the diffusion properties of neurochemicals in brain tissue are likely different in vivo from in vitro, dialysate values were not corrected for the recovery of the probe. Rather, determining the recovery of the probe allowed us to discard probes that were not within the normal range of recovery $(10-14 \%)$. The aCSF was continuously perfused through the probe at a rate of $1.5 \mu \mathrm{l} /$ minute by a microliter infusion pump (Harvard Apparatus, South Natick, MA).

\section{Surgical Procedures}

Animals were anesthetized with chloral hydrate (400 $\mathrm{mg} / \mathrm{kg} \mathrm{IP}$ ) and placed in a stereotaxic apparatus with 
the skull flat. A small burr hole was made in the skull centered $3.8 \mathrm{~mm}$ posterior and $2.0 \mathrm{~mm}$ lateral to bregma. The probe was slowly lowered $3.8 \mathrm{~mm}$ from the dura into the dorsal hippocampus and secured with skull screws and dental acrylic. The inlet of the probe was connected to a fluid swivel (Instech Laboratories Inc., Plymouth Meeting, PA), and the rat was placed into a cylindrical Plexiglass container and allowed to recover overnight. Dialysate samples were collected every 15 minutes until a stable baseline efflux (defined as three samples that did not vary by more than $10 \%$ ) was observed. In most cases, at the end of the experiment rats received an IP injection of the $\alpha_{2}$-agonist clonidine $(100 \mu \mathrm{g} / \mathrm{kg} \mathrm{IP})$ to verify the identity of the NE peak. At the end of the experiment rats were anesthetized and perfused transcardially with $10 \%$ buffered formalin. The brains were removed and stored in formalin. Subsequently $60-\mu \mathrm{m}$ frozen sections were cut on a microtome, mounted on gelatinized slides, and stained with cresyl violet to histologically verify placement of the dialysis probe. Data were discarded if the placement was observed to be outside of the hilar region of the dentate gyrus.

\section{NE Quantification}

The amount of NE in the dialysates was determined with high-pressure liquid chromatography coupled to electrochemical detection (HPLC-EC, see Abercrombie and Finlay 1991 for full description). Briefly, dialysate samples were collected at 15-minute intervals and $20 \mu \mathrm{l}$ were injected directly onto the HPLC, which consisted of an ESA 580 solvent delivery system, a Waters U6K injector, and a Velosep RP-18 column $(100 \times 3.2 \mathrm{~mm}, 3$ $\mu \mathrm{m}$; Brownlee Labs, Foster City, CA). The mobile phase consisted of $60 \mathrm{mM}$ sodium phosphate buffer ( $\mathrm{pH} 4.2$ ) with $100 \mu \mathrm{M}$ EDTA, $1.5 \mathrm{mM}$ sodium octyl-sulfate, and $3.5 \%(\mathrm{v} / \mathrm{v})$ methanol. The flow rate through the system was $700 \mu \mathrm{l} /$ minute. The detection system used was an ESA 5100A electrochemical detector with three electrodes in series. The conditioning electrode was set at $+270 \mathrm{mV}$. The applied potential of the second electrode was set at $-250 \mathrm{mV}$, and the compounds of interest were quantified at the third electrode, which was set at $+270 \mathrm{mV}$. Peak heights were measured and compared to the peak height of $10^{-8} \mathrm{M}$ standard calibrated daily. The sensitivity of this assay is 0.5 to $1.0 \mathrm{pg}$ of NE.

\section{Data Analysis}

The data are expressed as the mean \pm SEM. The effect of exposure to tailpinch on hippocampal NE efflux was analyzed using one-way ANOVA with repeated measures over time $(p<.05)$ coupled to Dunn's post-hoc test for comparison of treatment values to a baseline mean. The absolute amount of NE measured in dialy- sates (pg/20 $\mu \mathrm{l}$ sample) was used as the dependent variable to assess within-group effects; the value for the mean of the three final baseline samples and the values for four samples collected during and immediately after the tailpinch were analyzed. Between-group analyses of treatment differences were conducted using two-way ANOVA with repeated measures over time $(p<.05)$ coupled to Dunnett's post hoc test for comparison of group means relative to a control mean. To eliminate any potential contribution of baseline value differences to the overall treatment effects, the dependent variable employed in the between-group analyses was absolute change in NE $(\Delta p g)$ for the four samples collected during and immediately after the tailpinch relative to the baseline NE value. The level of significance for all posthoc analyses was $p<.01$.

\section{RESULTS}

\section{Controls}

The concentration of NE in dialysates from nonhandled control rats increased by $56 \%$ from $1.6 \pm 0.2 \mathrm{pg} / 20 \mu \mathrm{l}$ to $2.5 \pm 0.4 \mathrm{pg} / 20 \mu \mathrm{l}$ in response to tailpinch $[F(4,16)=$ $9.71, p<.001$; Figure 1]. In chronic vehicle control rats the stress-induced increase in NE of $39 \%$, from $1.8 \pm 0.2$ $\mathrm{pg} / 20 \mu \mathrm{l}$ to $2.5 \pm 0.2 \mathrm{pg} / 20 \mu \mathrm{l}$, was significant for the second stress sample, although there was no significant overall effect in this group $[F(4,16)=2.1, p=.13$; Figure 1]. However, between-group analysis revealed no signifi-

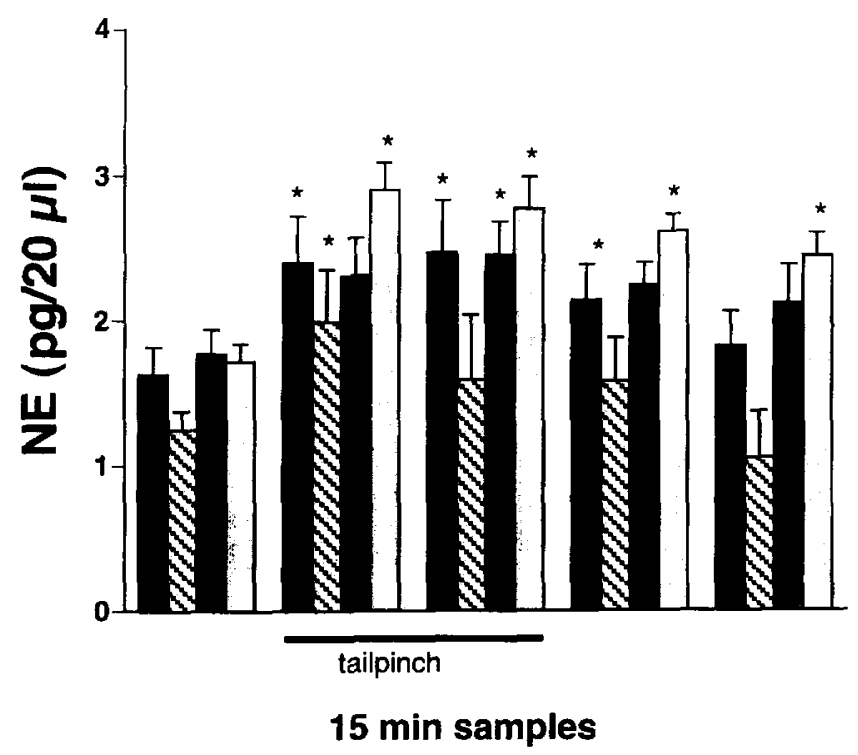

Figure 1. Effect of 30-minute tailpinch stress on hippocampal NE efflux in the experimental groups. Solid bars, controls; cross-hatched bars, acute flu; gray bars, chronic vehicle; open bars, chronic flu. For all groups $n=5-6$. Baseline values are the mean of three samples collected prior to tailpinch. Dunn's post hoc analysis: ${ }^{*} p<.01$ versus baseline. 
cant difference between naive controls and chronic vehicle controls in the absolute change in NE output in response to tailpinch $[F(1,8)=0.27, p=.62]$. In addition, there was no significant interaction of group and time $[F(3,24)=0.5, p=0.69]$. Posthoc analysis revealed no significant differences.

\section{Acute Fluoxetine}

Extracellular NE concentration did not differ significantly before and after fluoxetine administration; $1.3 \pm$ $0.2 \mathrm{pg} / 20 \mu \mathrm{l}$ versus $1.2 \pm 0.2 \mathrm{pg} / 20 \mu \mathrm{l}$ [data not shown, $F(4,1)=0.25, p=.64]$. Application of the tailpinch stimulus for 30 minutes increased NE efflux from $1.2 \pm 0.2$ $\mathrm{pg} / 20 \mu \mathrm{l}$ to $2.0 \pm 0.2 \mathrm{pg} / 20 \mu \mathrm{l}$, an increase of $67 \%$ $[F(4,16)=3.7, p=.03$; Figure 1]. There was no significant effect of group between acute fluoxetine and naive controls $[F(1,8)=1.33, p=.27]$, nor was there a significant interaction between the acute fluoxetine group and naive controls $[F(3,24)=0.84, p=.48$; Figure 2]. Posthoc analysis likewise revealed no significant differences.

\section{Chronic Fluoxetine}

Tailpinch significantly increased extracellular NE by $69 \%$, from $1.7 \pm 0.1 \mathrm{pg} / 20 \mu \mathrm{l}$ to $2.9 \pm 0.4 \mathrm{pg} / 20 \mu \mathrm{l}$ $[F(4,20)=9.84, p<.0001]$. NE was significantly elevated for the entire hour following the onset of the tailpinch stimulus in the chronic fluoxetine group, whereas a significant elevation in NE occurred only during the second stress sample in the control group (Figure 1). Comparison of the absolute change in NE output in response to tailpinch between the chronic fluoxetine group and the chronic vehicle group revealed no significant effect of group $[F(1,9)=2.73, p=.13]$. There was no significant interaction between these groups $[F(3,26)=1.00, p=.42]$. Post-hoc comparisons, however, revealed significantly greater NE output during the two stress samples in the chronic fluoxetine group (Figure 2).

\section{DISCUSSION}

Acute administration of fluoxetine did not significantly alter NE release evoked by tailpinch. Chronic fluoxetine administration, in contrast, produced an enhancement of the NE response to the tailpinch stimulus along with a significant prolongation of the time course of this response. Neither acute nor chronic fluoxetine altered the basal level of NE efflux in the hippocampus. These results on NE release in awake animals are similar to previous work by Valentino and colleagues (1990) examining LC unit activity in anesthetized rats. These authors showed that the evoked sensory response of LC neurons was somewhat enhanced in rats treated chronically with the SSRI sertraline. However, these authors also observed a decrease in the evoked LC response with acute sertraline.

Based on published data regarding the ability of serotonin to attenuate $\mathrm{LC}$ responsiveness to excitatory
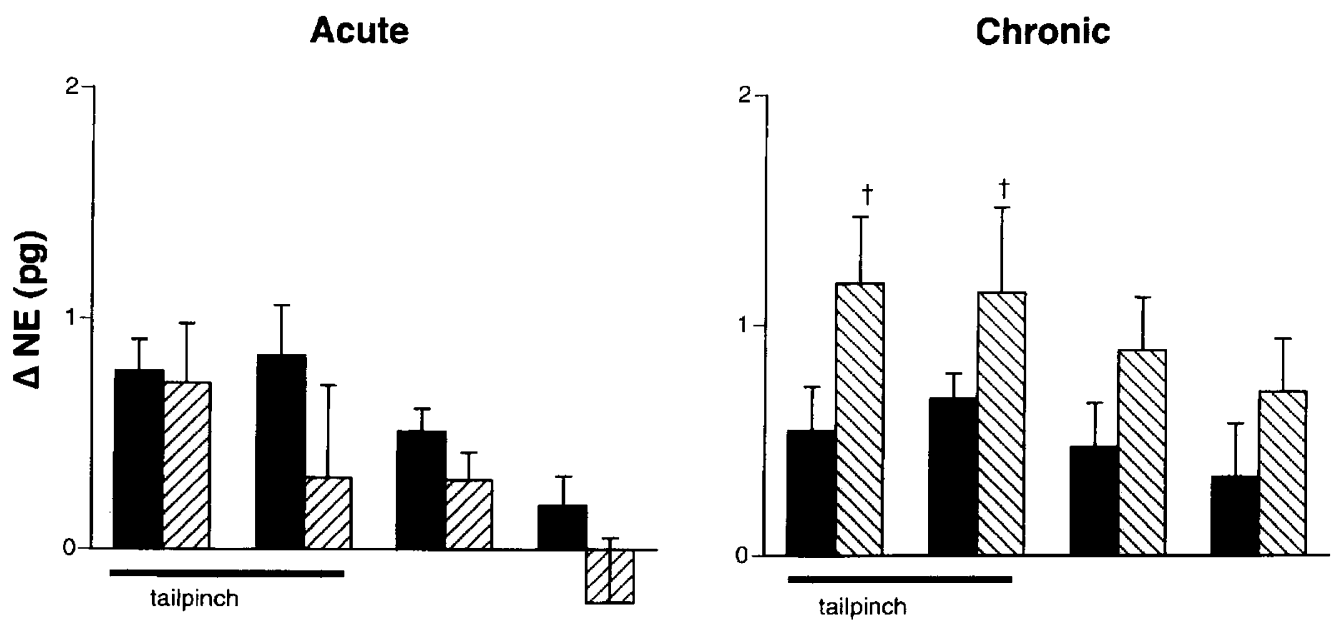

15 min samples

Figure 2. Left: effect of acute fluoxetine treatment $(n=5)$ on hippocampal NE output during and after tailpinch relative to unhandled controls $(n=5)$. Solid bars, vehicle; cross-hatched bars, fluoxetine. Right: effect of chronic fluoxetine treatment (cross-hatched bars, $n=6$ ) on hippocampal NE output during and after tailpinch relative to vehicle-treated controls (solid bars, $n=5$ ). $\Delta \mathrm{NE}(\mathrm{pg})$ is the absolute increase in NE obtained in the samples relative to the baseline mean (see text). The tailpinch stimulus was applied for 30 minutes. Dunnett's post hoc analysis: $p<.01$ versus control. 
stimuli (Segal 1979; Bobker and Williams 1989; Valentino et al 1990; Aston-Jones et al. 1991; Charlety et al. 1991), we hypothesized that acute fluoxetine administration would attenuate the tailpinch-induced release of NE. Acute fluoxetine previously has been shown to increase extracellular concentration of 5-HT in vivo (Perry and Fuller 1992; Sabol et al. 1992; Rutter and Auerbach 1993; Rutter et al. 1994), and a number of studies have shown that $5-\mathrm{HT}$ within the LC is able to attenuate evoked responses of LC neurons to noxious sensory stimuli or to glutamate (see Introduction). Although we observed a trend toward a diminished NE response to tailpinch after acute fluoxetine, this effect did not reach statistical significance. As described, the predicted decrease in an evoked sensory response of LC neurons was obtained in the study of Valentino et al. (1990). The failure to observe a significant decrease in evoked NE release in the present study may be due to the differences in temporal resolution of single-unit recording of LC activity versus microdialysis monitoring of NE efflux.

We found that the group of animals exposed to fluoxetine for 14 days exhibited a greater increase in NE release in response to tailpinch. Although testing in this group occurred 18 to 20 hours after the final dose of fluoxetine, drug washout is unlikely to be a factor in this result because the elimination half-life of fluoxetine is 8 to 13 hours and the metabolite, norfluoxetine, has a half-life of 15 to 16 hours and also is an active 5-HT reuptake blocker (Caccia et al. 1990; Gardier et al. 1993). Rather, this result presumably reflects the occurrence of cellular adaptation to chronically elevated extracellular concentration of 5-HT (Bel and Artigas 1993; Rutter et al. 1994; Kreiss and Lucki 1995). Previous work has demonstrated an involvement of the $5-\mathrm{HT}_{1 \mathrm{~A} / 1 \mathrm{~B}}$ receptor subtypes in the serotonergic inhibition of glutamatergic responses in LC (Bobker and Williams 1989; Charlety et al. 1991). These latter data are consistent with the distribution of 5-HT receptor subtypes (Pazos and Palacios 1985; Weissman-Nanopoulos et al. 1985). Li et al. (1993) observed that long-term (21-day) treatment with fluoxetine, but not desipramine, decreased $5-\mathrm{HT}_{1 \mathrm{~A}}$ receptor function in the hypothalamus. Likewise, Neumaier et al. (1996) demonstrated decreased 5-HT ${ }_{1 B}$ mRNA in the dorsal raphe following 21 days of fluoxetine treatment. It remains unknown whether such receptor changes occur in other brain regions, including the LC. If indeed downregulation of $5-\mathrm{HT}_{1 \mathrm{~A} / \mathrm{B}}$ receptor function occurs in the LC with chronic fluoxetine treatment, the antidepressant activity of fluoxetine may be expressed, in part, as an increase in the evoked responsivity of LC neurons.

The present data suggest that the antidepressant efficacy of SSRIs such as fluoxetine may involve a timedependent ability of the drug to enhance the activation of LC neurons by environmental stimuli. This suggestion implies that hyporesponsivity of the LC system may be a factor in the neural basis of depression. Unfortunately, neither the basic nor the clinical literature provides clear answers regarding possible alterations in central noradrenergic function that might occur in depressed individuals. Chronic stress has been implicated in the etiology of affective disorders (Redmond and Huang 1979; Charney et al. 1993; Abercrombie and Zigmond 1995) and therefore has been used as a paradigm for depression in animal models. In rats, exposure to severe or chronic uncontrollable stress can lead to a performance deficit on subsequent exposure to a similar or different stressor (Seligman and Maier 1967; Weiss and Simson 1985), and SSRIs have proven effective in reversing stress-induced behavioral deficits (Sherman and Petty 1980). Chronic stress has been shown to result in increased tissue concentration of NE (Irwin et al. 1986; Adell et al. 1988), increased activity of tyrosine hydroxylase in LC neurons (Thoenen 1970; Zigmond et al. 1974; Stone et al. 1978; Richard et al. 1988), and enhanced NE turnover in response to an acute stress (Thierry et al. 1968; Kvetnansky et al. 1983; Nisenbaum et al. 1991; Petty et al. 1994). To the extent that the noradrenergic changes reported in these animal studies do indeed reflect the biochemical alterations that exist in clinical depression, it would appear that hyper- rather than hyporesponsivity of the LC system may underly some of the symptoms of this disorder. On the other hand, a recent report shows that animals selectively bred for a predisposition to stress-induced behavioral depression display decreases in a number of indices of central noradrenergic function (Scott et al. 1996). Data from in vivo neurochemical studies using an animal model of depression to study antidepressant action(s) should be informative.

Finally, it is recognized that clinical depression is not a unitary disorder and that multiple subtypes with different etiologies likely exist. In this regard, it is interesting to note the recent data of Schildkraut and coworkers showing that patients with low urinary concentration of the NE metabolite 3-methoxy-4-hydroxyphenylglycol (MHPG) responded more favorably to treatment with fluoxetine than did patients with high MHPG concentrations (Schatzberg and Schildkraut 1995). An ability of fluoxetine to restore adequate levels of responsivity to environmental stimuli in the LC system may contribute to this clinical profile of the drug (present study; Valentino et al. 1990). The results we obtained reflect the diverse actions of fluoxetine on central monoaminergic systems.

\section{ACKNOWLEDGMENTS}

We thank Eli Lilly for the gift of Fluoxetine. This work was supported by PHS DA08086 (EDA) and MH10969 (MEP). EDA is an Alfred P. Sloan Foundation Research Fellow. 


\section{REFERENCES}

Abercrombie ED, Finlay JM (1991): Monitoring extracellular norepinephrine in brain using in vivo microdialysis and HPLC-EC. In Robinson TJ, Justice Jr. J (eds), Microdialysis in the Neurosciences, Amsterdam, Elsevier Scientific Publishers, pp 253-274

Abercrombie ED, Jacobs BL (1987): Single-unit response of noradrenergic neurons in the locus coeruleus of freely moving cats. I. Acutely presented stressful and nonstressful stimuli. J Neurosci 7:2837-2843

Abercrombie ED, Zigmond MJ (1995): Modification of central catecholaminergic systems by stress and injury. In Bloom FE, Kupfer DJ (eds), Psychopharmacology. The Fourth Generation of Progress, New York, Raven Press, pp 355-361

Abercrombie ED, Keller RW, Zigmond MJ (1988): Characterization of hippocampal norepinephrine release as measured by microdialysis perfusion: Pharmacological and behavioral studies. Neuroscience 27:897-904

Adell A, Garcia-Marquez C, Armario A, Gelpi E (1988): Chronic stress increases serotonin and noradrenaline in rat brain and sensitizes their responses to a further acute stress. J Neurochem 50:1678-1681

Anisman H, Zacharko RM (1982): Depression: The predisposing influence of stress. Behav Brain Sci 5:89-137

Aston-Jones G, Akaoka, H, Charlety P, Chouvet G (1991): Serotonin selectively attenuates glutamate-evoked activation of noradrenergic locus coeruleus neurons. J Neurosci 11:760-769

Baldwin D, Rudge S (1995): The role of serotonin in depression and anxiety. Int Clin Psychopharmacol 9(suppl 4):41-45

Bel N, Artigas F (1993): Chronic treatment with fluvoxamine increases extracellular serotonin in frontal cortex but not in raphe nuclei. Synapse 15:243-245

Bobker DH, Williams JT (1989): Serotonin agonists inhibit synaptic potentials in the rat locus ceruleus in vitro via 5-hydroxytryptamine ${ }_{1 \mathrm{~A}}$ and 5-hydroxytryptamine $\mathrm{B}_{\mathrm{B}}$ recep- $^{-}$ tors. J Pharmacol Exp Ther 250:37-43

Byerley WF, McConnell EJ, McCabe RT, Dawson TM, Grosser BI, Wamsley JK (1988): Decreased beta-adrenergic receptors in rat brain after chronic administration of the selective serotonin uptake inhibitor fluoxetine. Psychopharmacology 94:141-143

Caccia S, Cappi M, Fracasso C, Garattini S (1990): Influence of dose and route of administration on the kinetics of fluoxetine and its metabolite norfluoxetine in the rat. Psychopharmacology 100:509-514

Caccia S, Fracasso C, Garattini G, Guiso G, Sarati S (1992): Effects of short- and long-term administration of fluoxetine on the monoamine content of rat brain. Neuropharmacology 31:343-347

Charlety PI, Aston-Jones G, Akaoka H, Buda M, Chouvet G (1991): 5-HT decreases glutamate-evoked activation of locus coeruleus neurons through $5-\mathrm{HT}_{1 \mathrm{~A}}$ receptors. $\mathrm{C} \mathrm{R}$ Aca Sci Paris 312:421-426

Charney DS, Deutch AY, Krystal JH, Southwick SM, Davis M (1993): Psychobiologic mechanisms of posttraumatic stress disorder. Arch Gen Psychiatr 50:294-305

Corley KC, Singh VB, Phan T-H, Boadle-Biber MC (1992):
Effect of gepirone on increases in tryptophan hydroxylase in response to sound stress. Eur J Pharmacol 213:417-425

Curtis AL, Drolet G, Valentino RJ (1993): Hemodynamic stress activates locus coeruleus neurons of unanesthetized rats. Brain Res Bull 31:737-744

Dunn A (1988): Stress-related changes in cerebral catecholamine and indoleamine metabolism: Lack of effect of adrenalectomy and corticosterone. J Neurochem 51:406412

el Mansari M, Bouchard C, Blier P (1995): Alteration of serotonin release in the guinea pig orbito-frontal cortex by selective serotonin reuptake inhibitors. Relevance to treatment of obsessive-compulsive disorder. Neuropsychopharmacology 13:117-127

Elam M, Yao T, Thoren P. Svensson T (1986): Locus coeruleus neurons and sympathetic nerves: Activation by visceral afferents. Brain Res 375:117-125

Gardier AM, Lepoul E, Trouvin JH, Chanut E, Dessalles MC, Jacquot C (1993): Changes in dopamine metabolism in rat forebrain regions after cessation of long-term fluoxetine treatment: Relationship with brain concentrations of fluoxetine and norfluoxetine. Life Sci 54:PL51-56

Heninger GR, Charney DS (1987): Mechanism of action of antidepressant treatments: Implications for the etiology and treatment of depressive disorders. In Meltzer HY (ed), Psychopharmacology. The Third Generation of Progress, New York, Raven Press, pp 535-544

Irwin J, Ahluwalia P, Anisman H (1986): Sensitization of norepinephrine activity following acute and chronic footshock. Brain Res 379:98-103

Iversen LL (1975): Uptake processes for biogenic amines. In Iversen LL, Iversen SD, Snyder SH (eds), Handbook of Psychopharmacology, vol 3, New York, Plenum, pp $381-442$

Kalen P, Rosegren E, Lindvall O, Bjorklund A (1989): Hippocampal noradrenaline and serotonin release over 24 hours as measured by the dialysis technique in freely moving rats: Correlation to behavioural activity state, effect of handling and tail-pinch. Eur J Neurosci 1:181188

Korf J, Aghajanian GK, Roth RH (1973): Increased turnover of norepinephrine in the rat cerebral cortex during stress: Role of the locus coeruleus. Neuropharmacology $12: 933-938$

Kreiss D, Lucki I (1995): Effects of acute and repeated administration of antidepressant drugs on extracellular levels of 5-hydroxytryptamine measured in vivo. J Pharmacol Exp Ther 274:866-876

Kvetnansky R, Nemeth S, Vigas M, Oprsalova Z, Jurcovicova J (1983): Plasma catecholamines in rats during adaptation to intermittent exposure to different stressors. In Usdin E, Kvetnansky R, Axelrod J (eds), Stress: The role of catecholamines and other neurotransmitters, vol 1, New York, Gordon and Breach, pp 537-562

Leger L, Descarries L (1978): Serotonin nerve terminals in the locus coeruleus of adult rat: A radioautographic study. Brain Res 145:1-13

Li Q, Levy AD, Cabrera TM, Brownfield MS, Battaglia G, Van der Kar LD (1993): Long-term fluoxetine, but not desipramine, inhibits the ACTH and oxytocin responses 
to the $5-\mathrm{HT}_{1 \mathrm{~A}}$ agonist, 8-OH-DPAT, in male rats. Brain Res 630:215-221

Morilak DA, Fornal C, Jacobs BL (1987): Effects of physiological manipulations on locus coeruleus neuronal activity in freely moving cats. I. Thermoregulatory challenge. Brain Res 422:17-23

NIH (National Institutes of Health) (1985): Guide for Care and Use of Laboratory Animals. Washington DC

Neumaier JF, Root DC, Hamblin MW (1996): Chronic fluoxetine reduces serotonin transporter $\mathrm{mRNA}$ and $5-\mathrm{HT}_{1 \mathrm{~B}}$ mRNA in a sequential manner in the rat dorsal raphe nucleus. Neuropsychopharmacology 15:515-522

Nisenbaum LK, Zigmond MJ, Sved AF, Abercrombie ED (1991): Prior exposure to chronic stress results in enhanced synthesis and release of norepinephrine in response to a novel stressor. J Neurosci 11:1478-1484

Owens MJ, Nemeroff CB (1994): The role of serotonin in the pathophysiology of depression: Focus on the serotonin transporter. Clin Chem 40:288-295

Palkovits M, Brownstein M, Saavedra JM (1974): Serotonin content of the brain stem nuclei in the rat. Brain Res 80:237-249

Pazos A, Palacios JM (1985): Quantitative autoradiographic mapping of serotonin receptors in the rat brain. I. Serotonin-1 receptors. Brain Res 346:205-230

Perry KW, Fuller RW (1992): Effect of fluoxetine on serotonin and dopamine concentration in microdialysis fluid from rat striatum. Life Sci 50:1683-1690

Petty F, Chae Y-I, Kramer G, Jordan S, Wilson LA (1994): Learned helplessness sensitizes hippocampal norepinephrine to mild restress. Biol Psychiatr 35:903-908

Pickel VM, Joh TH, Reis DJ (1977): A serotonergic innervation of noradrenergic neurons in nucleus locus coeruleus: Demonstration by immunocytochemical localization of the transmitter specific enzymes tyrosine hydroxylase and tryptophan hydroxylase. Brain Res 131:197-214

Redmond DE, Huang YH (1979): New evidence for a locus coeruleus-norepinephrine connection with anxiety. Life Sci 25:2149-2162

Richard F, Faucon-Biguet N, Labautu R, Rollet D, Malle J, Buda M (1988): Modulation of tyrosine hydroxylase gene expression in rat brain and adrenals by exposure to cold. J Neurosci Res 20:32-37

Richelson E, Pfenning M (1984): Blockade by antidepressants and related compounds of biogenic amine uptake into rat brain synaptosomes: Most antidepressants selectively block norepinephrine uptake. Eur J Pharmacol 104:277-286

Rutter JJ, Auerbach S (1993): Acute uptake inhibition increases extracellular serotonin in the rat forebrain. I Pharmacol Exp Ther 265:1319-1324

Rutter J], Gundlah C, Auerbach S (1994): Increase in extracellular serotonin produced by uptake inhibitors is enhanced after chronic treatment with fluoxetine. Neurosci Lett 171:183-186

Sabol KE, Richards JB, Seiden LS (1992): Fluoxetine attenuates the fenfluramine induced increase in extracellular serotonin as measured by in vivo dialysis. Brain Res $585: 421-424$
Schatzberg AF, Schildkraut JJ (1995): Recent studies on norepinephrine systems in mood disorders. In Bloom FE, Kupfer DJ (eds), Psychopharmacology: The Fourth Generation of Progress, Raven, New York, pp 911-920

Schildkraut JJ (1965): The catecholamine hypothesis of affective disorders, a review of the supporting evidence. Am J Psychiatr 12:509-522

Scott PA, Cierpial MA, Kilts CD, Weiss JM (1996): Susceptibility and resistance of rats to stress-induced decreases in swim-test activity: A selective breeding study. Brain Res 725:217-230

Segal M (1979): Serotonergic innervation of the locus coeruleus from the dorsal raphe and its action on responses to noxious stimuli. J Physiol (Lond) 286:401-415

Seligman MEP, Maier SF (1967): Failure to escape traumatic shock. J Exp Psychol 74:1-9

Sherman AD, Petty F (1980): Neurochemical basis of the action of antidepressants on learned helplessness. Behav Neural Bio 30:119-134

Shiekhattar R, Aston-Jones G (1993): Sensory responsiveness of brain noradrenergic neurons is modulated by endogenous brain serotonin. Brain Res 623:72-76

Stanford SC (1996): Prozac: Panacea or puzzle? TiPS 17:150154

Stone EA, Freedman LS, Morgano LE (1978): Brain and adrenal tyrosine hydroxylase activity after chronic footshock stress. Pharmacol Biochem Behav 9:551-553

Thierry AM, Javoy J, Glowinski J, Kety SS (1968): Effects of stress on the metabolism of norepinephrine, dopamine and serotonin in the central nervous system of the rat. I. Modifications of norepinephrine turnover. J Pharmacol Exp Ther 163:163-171

Thoenen H (1970): Induction of tyrosine hydroxylase in peripheral and central adrenergic neurones by coldexposure of rats. Nature 228:861-862

Trouvin JH, Gardier AM, Chanut E, Pages N, Jacquot C (1993): Time course of brain serotonin metabolism after cessation of long-term fluoxetine treatment in the rat. Life Sci 52:187-192

Valentino R, Curtis AL, Parris DG, Wehby RG (1990): Antidepressant actions on brain noradrenergic neurons. J Pharmacol Exp Ther 253:833-840

Weiss JM, Simson PG (1985): Neurochemical basis of stressinduced depression. Psychopharmacol Bull 21:447-457

Weissman-Nanopoulos D, Mach E, Magre J, De Massey Y, Pujol JF (1985): Evidence for the localization of $5-\mathrm{HT}_{1 \mathrm{~A}}$ binding site on serotonin-containing neurons in the raphe dorsalis and raphe centralis nuclei of the rat brain. Neurochem Int 7:1061-1072

Wong DT, Bymaster FP, Engleman EA (1995): Prozac (Lilly 110140), the first selective serotonin uptake inhibitor and an antidepressant drug: Twenty years since its first publication. Life Sci 57:411-441

Zigmond RE, Schon F, Iversen LL (1974): Increased tyrosine hydroxylase activity in the locus coeruleus of rat brain stem after reserpine treatment and cold stress. Brain Res $70: 547-552$ 